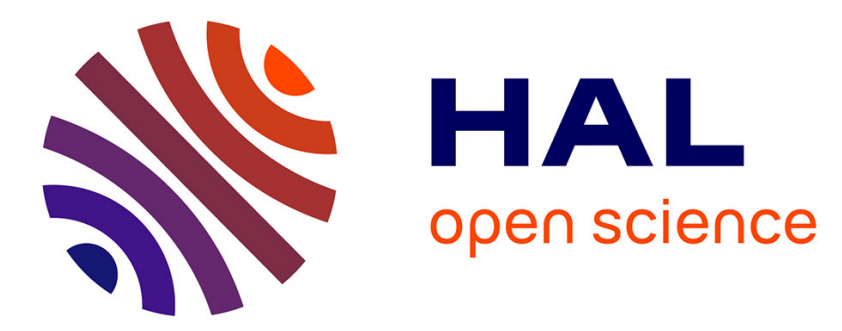

\title{
Tunneling anisotropic magnetoresistance in fully epitaxial magnetic tunnel junctions with different barriers
}

B S Tao, L N Jiang, W J Kong, W Z Chen, Bin Yang, X. Wang, C. Wan, H. Wei, M. Hehn, D. Lacour, et al.

\section{To cite this version:}

B S Tao, L N Jiang, W J Kong, W Z Chen, Bin Yang, et al.. Tunneling anisotropic magnetoresistance in fully epitaxial magnetic tunnel junctions with different barriers. Applied Physics Letters, 2018, 112 (24), 10.1063/1.5027909 . hal-02388308

\section{HAL Id: hal-02388308 https://hal.science/hal-02388308}

Submitted on 1 Dec 2019

HAL is a multi-disciplinary open access archive for the deposit and dissemination of scientific research documents, whether they are published or not. The documents may come from teaching and research institutions in France or abroad, or from public or private research centers.
L'archive ouverte pluridisciplinaire HAL, est destinée au dépôt et à la diffusion de documents scientifiques de niveau recherche, publiés ou non, émanant des établissements d'enseignement et de recherche français ou étrangers, des laboratoires publics ou privés. 


\section{Tunneling anisotropic magnetoresistance in fully epitaxial magnetic tunnel junctions with different barriers}

B. S. Tao, L. N. Jiang, W. J. Kong, W. Z. Chen, B. S. Yang, X. Wang, C. H. Wan, H. X. Wei, M. Hehn, D. Lacour, Y. Lu, and X. F. Han

Citation: Appl. Phys. Lett. 112, 242404 (2018); doi: 10.1063/1.5027909

View online: https://doi.org/10.1063/1.5027909

View Table of Contents: http://aip.scitation.org/toc/apl/112/24

Published by the American Institute of Physics

\section{Articles you may be interested in}

Switching current reduction using $\mathrm{MgO}$ cap layer in magnetic tunnel junctions

Applied Physics Letters 112, 242408 (2018); 10.1063/1.5035379

Perpendicular magnetic tunnel junction performance under mechanical strain

Applied Physics Letters 112, 232401 (2018); 10.1063/1.5034145

Chiral anisotropic magnetoresistance of ferromagnetic helices

Applied Physics Letters 112, 242401 (2018); 10.1063/1.5027660

Spin-hall-active platinum thin films grown via atomic layer deposition

Applied Physics Letters 112, 242403 (2018); 10.1063/1.5025472

High performance perpendicular magnetic tunnel junction with Co/Ir interfacial anisotropy for embedded and standalone STT-MRAM applications

Applied Physics Letters 112, 092402 (2018); 10.1063/1.5018874

Tuning Slonczewski-like torque and Dzyaloshinskii-Moriya interaction by inserting a Pt spacer layer in Ta/ $\mathrm{CoFeB/MgO} \mathrm{structures}$

Applied Physics Letters 112, 232402 (2018); 10.1063/1.5026423

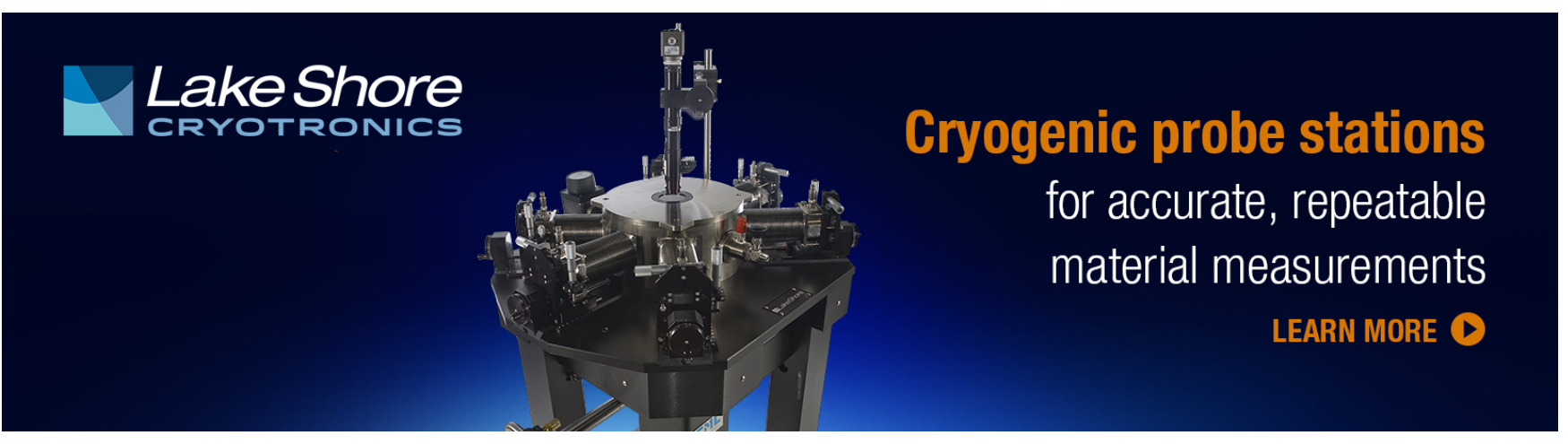




\title{
Tunneling anisotropic magnetoresistance in fully epitaxial magnetic tunnel junctions with different barriers
}

\author{
B. S. Tao, ${ }^{1,2,3}$ L. N. Jiang, ${ }^{2}$ W. J. Kong, ${ }^{2}$ W. Z. Chen, ${ }^{2}$ B. S. Yang,${ }^{2}$ X. Wang, ${ }^{2}$ C. H. Wan, ${ }^{2}$ \\ H. X. Wei, ${ }^{2}$ M. Hehn, ${ }^{3}$ D. Lacour, ${ }^{3}$ Y. Lu, ${ }^{3, a)}$ and X. F. Han ${ }^{2, a)}$ \\ ${ }_{1}^{1}$ Institute of Electrical Engineering, Chinese Academy of Sciences, Beijing 100190, China \\ ${ }^{2}$ Beijing National Laboratory of Condensed Matter Physics, Institute of Physics, University of Chinese \\ Academy of Sciences, Chinese Academy of Sciences, Beijing 100190, China \\ ${ }^{3}$ Institut Jean Lamour, UMR 7198, CNRS-Université de Lorraine, BP239, 54506 Vandoeuvre-lès-Nancy, \\ France
}

(Received 7 March 2018; accepted 27 May 2018; published online 12 June 2018)

\begin{abstract}
We report the tunneling anisotropic magnetoresistance (TAMR) in fully epitaxial $\mathrm{Fe} /$ Barrier/Fe (001) magnetic tunnel junctions (MTJs) where the Barrier is annealed $\mathrm{MgO}, \mathrm{MgAlO}_{\mathrm{x}}, \mathrm{MgO}-$ $\mathrm{MgAlO}_{\mathrm{x}}$, or as-grown $\mathrm{MgO} / \mathrm{MgAlO}_{\mathrm{x}}$. The TAMR was measured as the magnetization of Fe electrodes rotated from in-plane to out-of-plane. The angular dependence of TAMR for all samples exhibited superposed behavior of twofold and fourfold symmetries. The proportion of fourfold symmetry is larger in MTJs with $\mathrm{MgO}$ and $\mathrm{MgO}-\mathrm{MgAlO}_{\mathrm{x}}$ than that in MTJs with $\mathrm{MgAlO}_{\mathrm{x}}$ and $\mathrm{MgO} / \mathrm{MgAlO}_{\mathrm{x}}$ barriers. By characterizing inelastic electron tunneling spectroscopy in the antiparallel state and parallel conductance of the MTJs, we revealed diverse minority interfacial resonant states (IRSs) and different contributions from $\Delta_{1}$ and $\Delta_{5}$ symmetry states to the conductance in the MTJs. Our results illustrate that the minority IRS dominated by $\Delta_{5}$ symmetry can mix with majority $\Delta_{1}$ states and give rise to the enhanced fourfold symmetric angular dependence in MTJs with $\mathrm{MgO}$ and $\mathrm{MgO}-\mathrm{MgAlO}_{\mathrm{x}}$ barriers. Published by AIP Publishing. https://doi.org/10.1063/1.5027909
\end{abstract}

Tunneling magnetoresistance (TMR) in magnetic tunnel junctions (MTJs) has been extensively studied ${ }^{1-5}$ due to its important applications in spintronic devices. The TMR originates from spin-dependent tunneling between two ferromagnetic electrodes through a thin barrier. Different from TMR, tunneling anisotropic magnetoresistance (TAMR), which is caused by the interplay between anisotropic density of states (DOS) of magnet and magnetization, requires only one magnetic electrode in the junctions. ${ }^{6,7}$ The simplicity of the structures for TAMR is attractive for applications and has attracted much attention. ${ }^{6,8-14}$ The anisotropy of DOS with respect to the magnetization direction is attributed to spin-orbit coupling (SOC). ${ }^{9,10}$ Relatively large TAMR was observed in junctions consisting of materials with strong SOC, such as GaMnAs ${ }^{8,15}$ and $\mathrm{Pt}^{13}$ Furthermore, a finite TAMR was also noticed in MTJs with transition metal ${ }^{11-13,16}$ despite the weak SOC in the system.

The TAMR in $\mathrm{AlO}_{\mathrm{x}}$ or $\mathrm{MgO}$ barrier based MTJs has been experimentally reported, ${ }^{11,13,16,17}$ and the angular dependence with twofold and fourfold components was observed, which is attributed to minority interfacial resonant states (IRSs) coupled to $\Delta_{1}$ states. ${ }^{11}$ In epitaxial $\mathrm{Fe} / \mathrm{MgO} / \mathrm{Fe}$ MTJ, different minority IRSs have been revealed ${ }^{17,18}$ and a relatively large TAMR was observed ${ }^{17}$ due to the shift of the resonant surface band via the Rashba effect. ${ }^{10}$ It seems that the minority IRSs have a significant impact on TAMR. Recently, the $\mathrm{MgAlO}_{\mathrm{x}}$ oxide with the spinel structure has been investigated as a promising candidate for the MTJ barrier due to its smaller lattice mismatch with a usual ferromagnetic electrode. ${ }^{19-24}$ An improved bias dependence of TMR ${ }^{19,25}$ and enhanced quantum well states ${ }^{26}$ in

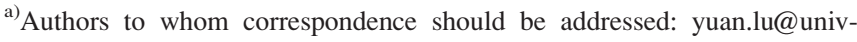
lorraine.fr and xfhan@iphy.ac.cn
}

$\mathrm{MgAlO}_{\mathrm{x}}$ barrier based MTJs have been realized owing to the high quality of the $\mathrm{MgAlO}_{\mathrm{x}} /$ ferromagnet interfaces. The IRSs, which impact the TAMR effect, should be modified in MTJs with different barriers. In this work, we studied the TAMR and its angular dependence in fully epitaxial MTJs with four kinds

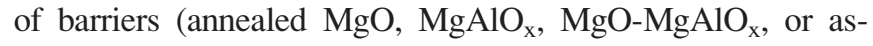
grown $\mathrm{MgO} / \mathrm{MgAlO}_{\mathrm{x}}$ barrier), where different IRSs were observed by inelastic electron tunneling spectroscopy (IETS) in the different samples. The TAMR displayed different symmetries of angular dependence, and its relationship with IRSs has been discussed.

MTJs with different barriers were grown on $\mathrm{MgO}$ substrates by molecular beam epitaxy (MBE) with the following structure: $\mathrm{Fe}(45 \mathrm{~nm}) /$ Barrier $/ \mathrm{Fe}(10 \mathrm{~nm}) / \mathrm{Co}(20 \mathrm{~nm}) / \mathrm{Au}(15 \mathrm{~nm})$. Before depositing the multilayers, the $\mathrm{MgO}$ substrate was first annealed at $650^{\circ} \mathrm{C}$ for $30 \mathrm{~min}$ and $10 \mathrm{~nm} \mathrm{MgO}$ seed layer was deposited. The bottom Fe of all the samples was annealed in situ at $500^{\circ} \mathrm{C}$ for $30 \mathrm{~min}$ to flatten the surface. Then, the Barrier layers were deposited at room temperature (RT). The thickness is controlled by the intensity oscillation of reflective high energy electron diffraction (RHEED) with monolayer (ML) precision. Three samples were prepared with the Barrier of $\mathrm{MgO}(12 \mathrm{ML}), \mathrm{MgAlO}_{\mathrm{x}}(12 \mathrm{ML})$, or $\mathrm{MgO}(5 \mathrm{ML}) / \mathrm{MgAlO}_{\mathrm{x}}(7 \mathrm{ML})$. The top Fe of the three samples was annealed at $400{ }^{\circ} \mathrm{C}$ to improve the quality of crystallinity. Hereafter, they are named as $\mathrm{MgO}, \mathrm{MgAlO}_{\mathrm{x}}$, and $\mathrm{MgO}-$ $\mathrm{MgAlO}_{\mathrm{x}} \mathrm{MTJ}$, respectively. For comparison, another sample with a $\mathrm{MgO}(5 \mathrm{ML}) / \mathrm{MgAlO}_{\mathrm{x}}(7 \mathrm{ML})$ barrier but the top $\mathrm{Fe}$ without any annealing was deposited to avoid the mixture of $\mathrm{MgO}$ and $\mathrm{MgAlO}_{\mathrm{x}}$ during annealing, ${ }^{25}$ hereafter, named as $\mathrm{MgO} / \mathrm{MgAlO}_{\mathrm{x}} \mathrm{MTJ}$. All the samples were patterned into junctions with a size of $20 \times 20 \mu \mathrm{m}^{2}$ by UV lithography combined with ion milling. The transport properties were 
measured by the two-probe method, where negative bias corresponds to the electrons tunneling from the top to bottom electrode. The TAMR measurement was performed at $10 \mathrm{~K}$ in a Physical Property Measurement System (PPMS) by measuring the differential resistance $R_{\mathrm{d}}=\mathrm{d} V / \mathrm{d} I$ using an AC lock-in method. The magnetic easy axis of the electrode, the film normal direction $\vec{n}$, and the magnetic field $\vec{H}$ were arranged in the same plane. The schematics of the measurement setup and structure of MTJs are shown in Fig. 1(a). $R_{\mathrm{d}}$ was measured as a function of angle $\theta$ between $\vec{H}$ and $\vec{n}$, where a magnetic field of $5 \mathrm{~T}$ was applied to saturate the magnetization of electrodes and the sample was rotated from $\theta=0^{\circ}$ to $\theta=360^{\circ}$.

Figure 1(b) shows the temperature dependence of the TMR ratio of all the samples at a bias voltage of $10 \mathrm{mV}$. A common feature is that the TMR ratio increases with the decreasing temperature, resulting from that $R_{\mathrm{AP}}$ increases rapidly while $R_{\mathrm{P}}$ varies slightly with decreasing temperature. As shown in Fig. 1(b), we can obtain a TMR ratio of $154 \%$ at room temperature (RT) and $305 \%$ at $20 \mathrm{~K}$ for MgO MTJ, indicating the high quality of $\mathrm{MgO}$ MTJ. A much lower TMR ratio at RT (74\%) and $20 \mathrm{~K}(121 \%)$ was gained for $\mathrm{MgAlO}_{\mathrm{x}}$ MTJ. This could be explained by the "band folding" effect of $\mathrm{Fe}$ in the $\mathrm{MgAlO}_{\mathrm{x}}$ barrier, ${ }^{21}$ which creates a new conductive channel in the minority states with $\Delta_{1}$ symmetry and reduces the effective spin-polarization of the $\mathrm{Fe}$

(a)
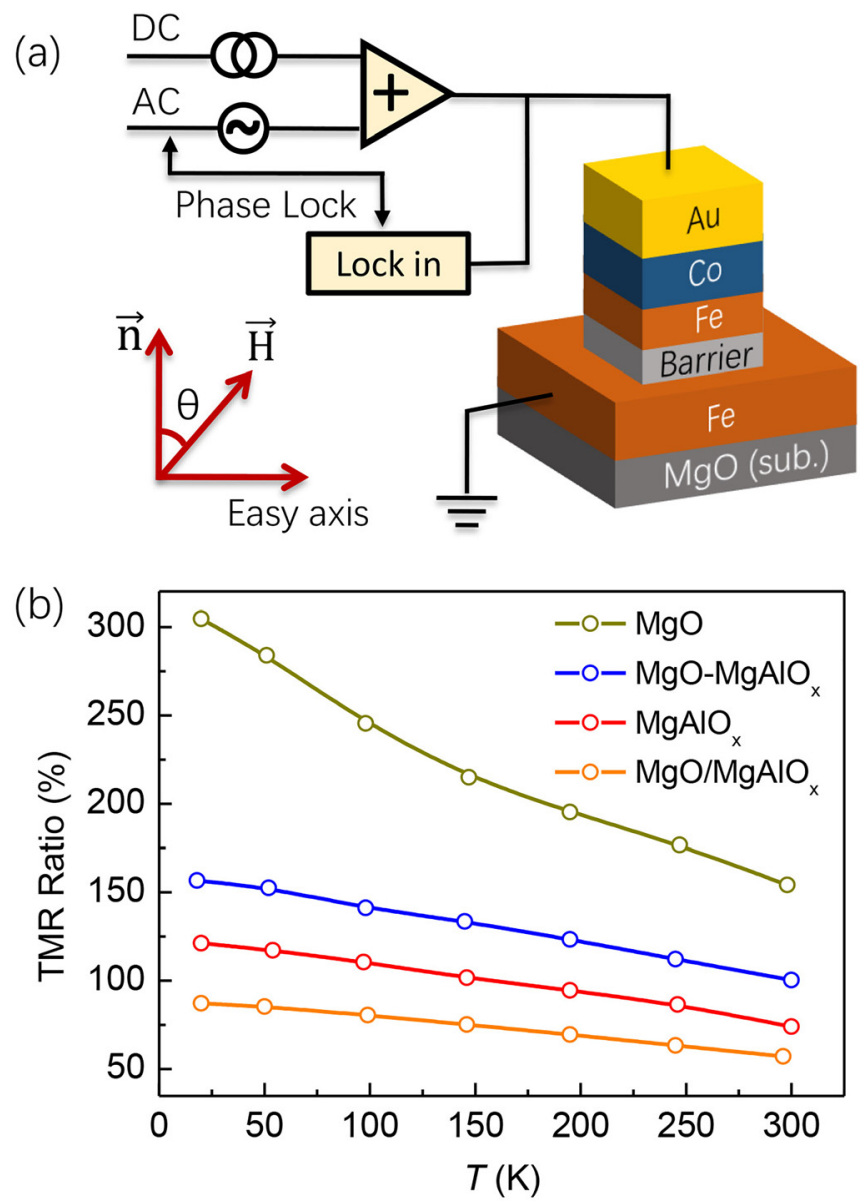

FIG. 1. (a) Schematics of the MTJ structure and measurement setup for TAMR by an AC lock in method and (b) temperature dependence of the TMR ratio of $\mathrm{MgO}, \mathrm{MgAlO}_{\mathrm{x}}, \mathrm{MgO}_{\mathrm{MgAlO}}$, and $\mathrm{MgO} / \mathrm{MgAlO}{ }_{\mathrm{x}}$ MTJs at a bias of $10 \mathrm{mV}$. electrode. The TMR ratio is improved in the composite $\mathrm{MgO}-\mathrm{MgAlO}_{\mathrm{x}} \mathrm{MTJ}$, which is $100 \%$ at RT and $157 \%$ at $20 \mathrm{~K}$, indicating a suppression of the "band folding" effect. While for $\mathrm{MgO} / \mathrm{MgAlO}_{\mathrm{x}}$ MTJ with un-annealed top $\mathrm{Fe}$, the TMR is only $57 \%$ at RT and $87 \%$ at $20 \mathrm{~K}$, which is even lower than that of $\mathrm{MgAlO}_{\mathrm{x}}$ MTJ. This result demonstrates that the annealing process is necessary to improve the TMR in fully epitaxial MTJs. ${ }^{27}$

The angular dependence of $R_{\mathrm{d}}$ with bias voltage from $-0.9 \mathrm{~V}$ to $0.9 \mathrm{~V}$ is shown in Figs. 2(a) $-2(\mathrm{~d})$ for $\mathrm{MgO}$, $\mathrm{MgAlO}_{\mathrm{x}}, \mathrm{MgO}-\mathrm{MgAlO}_{\mathrm{x}}$, and $\mathrm{MgO} / \mathrm{MgAlO}_{\mathrm{x}}$ MTJs, respectively, where $\phi$ denotes the angle between the Fe magnetization direction and film normal $\vec{n} . R_{\mathrm{d}}$ is normalized to its average value over $\theta$ at each bias. After taking into account the Zeeman and the demagnetization energy, the relation between $\theta$ and $\phi$ can be given by minimizing the total energy

$$
H M_{s} \sin (\phi-\theta)-2 \pi M_{s}^{2} \sin 2 \phi=0,
$$

where $H$ is the magnetic field and $M_{\mathrm{s}}$ is the saturation magnetization of Fe. The red solid curves are fitting results by the following equation:

$$
R_{\mathrm{d}}=A_{0}+A_{2} \cos 2 \phi+A_{4} \cos 4 \phi,
$$

where $A_{0}, A_{2}$, and $A_{4}$ are the fitting parameters. Taking $4 \pi M_{\mathrm{s}}=2.1 \mathrm{~T},{ }^{28}$ we can obtain very good agreement between data and fits.

For $\mathrm{MgO}$ and $\mathrm{MgO}-\mathrm{MgAlO}_{\mathrm{x}}$ MTJs, the angular dependence shows pronounced components of twofold and

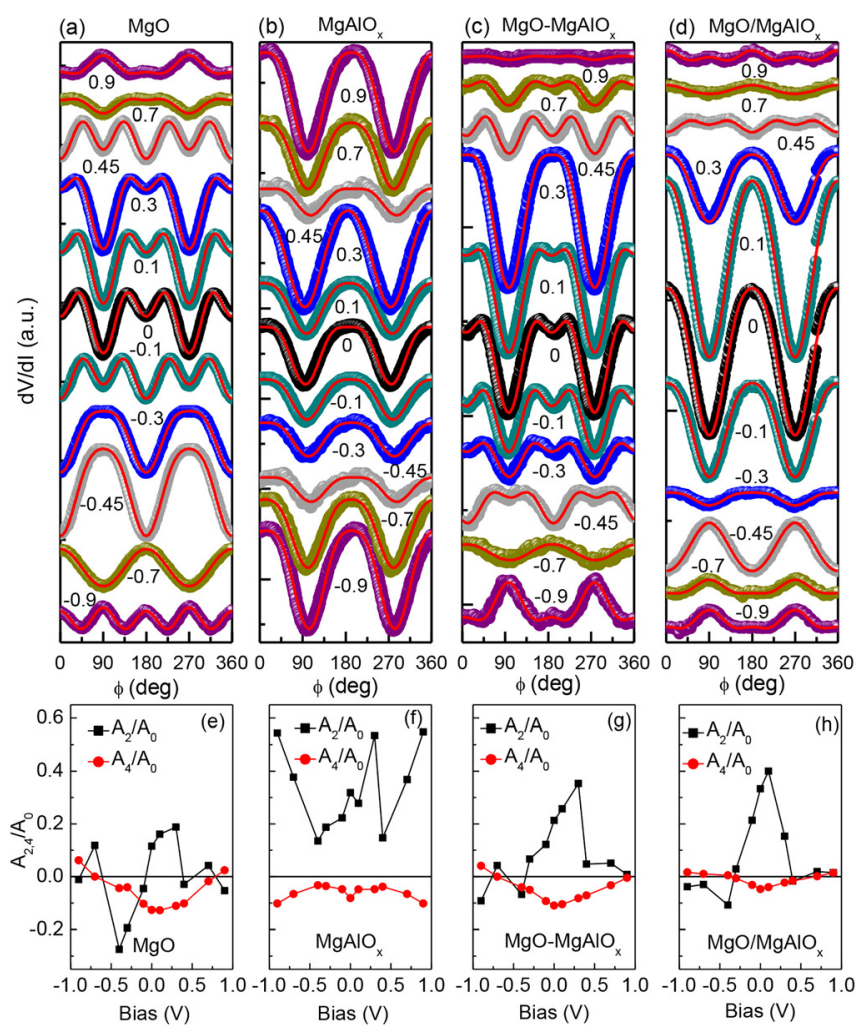

FIG. 2. Normalized $\mathrm{d} V / \mathrm{d} I$ as a function of $\phi$ at different bias for $\mathrm{MgO}$ (a), $\mathrm{MgAlO}_{\mathrm{x}}(\mathrm{b}), \mathrm{MgO}-\mathrm{MgAlO}_{\mathrm{x}}$ (c), and $\mathrm{MgO} / \mathrm{MgAlO}_{\mathrm{x}}$ (d), respectively, where symbols are experimental data and the red lines are fitting curves. The numbers in the figure denote the value of bias voltage. There is a vertical offset between different curves for clarity. (e) and (f) show the corresponding fitting parameters $A_{2} / A_{0}$ (black) and $A_{4} / A_{0}$ (red) dependence on bias. 
fourfold symmetries and the position of the $R_{\mathrm{d}}$ extrema changes at different bias. For $\mathrm{MgAlO}_{\mathrm{x}} \mathrm{MTJ}$, the TAMR curves are mainly dominated by twofold symmetry and the minimum of $R_{\mathrm{d}}$ is observed at $\phi=90^{\circ}$ and $270^{\circ}$ for all bias voltages, which is quite different from that of $\mathrm{MgO}$ MTJ. The angular dependence of $\mathrm{MgO} / \mathrm{MgAlO}_{\mathrm{x}} \mathrm{MTJ}$ is also dominated by the twofold component, but its extrema vary with bias. To estimate the proportion of twofold and fourfold components of angular dependence of $R_{\mathrm{d}}$, we plotted $A_{2} / A_{0}$ and $A_{4} / A_{0}$ as a function of bias as shown in Figs. 2(e)-2(h). For $\mathrm{MgAlO}_{\mathrm{x}} \mathrm{MTJ}$, the TAMR effect is much increased and the sign of $A_{2}$ and $A_{4}$ exhibits no change with bias. The proportion of twofold symmetry is much higher than that of fourfold symmetry. Generally, the angular dependence of the TAMR effect in MTJs is twofold-symmetrical. ${ }^{11,29}$ Thus, the enhancement of the TAMR effect in $\mathrm{MgAlO}_{\mathrm{x}}$ MTJ is mainly presented by $A_{2} / A_{0}$ and no much increase was observed in $A_{4} / A_{0}$. While for the other three samples, $A_{2}$ and $A_{4}$ change their sign with bias and $A_{4}$ shows a parabolic like behavior as a function of bias. In addition, $\mathrm{MgO} / \mathrm{MgAlO}_{\mathrm{x}}$ MTJ shows a much weaker fourfold component than $\mathrm{MgO}$ and $\mathrm{MgO}-$ $\mathrm{MgAlO}_{\mathrm{x}}$ MTJs.

To give a comprehensive perspective of the TAMR, Figs. 3(a)-3(d) show the normalized $R_{\mathrm{d}}$ as a function of bias voltage and angle $\theta$ with steps of $50 \mathrm{mV}$ and $2^{\circ}$, respectively. The magnitude of $R_{\mathrm{d}}$ is represented by the color in the plot. Noticeably, $\mathrm{MgAlO}_{\mathrm{x}}$ MTJ shows distinct features from the other three samples. The angular dependence of $\mathrm{MgAlO}_{\mathrm{x}}$ MTJ mainly shows a twofold symmetry, and the bias dependence is rather symmetric about zero bias. The minima of $R_{\mathrm{d}}$ are at $\theta=90^{\circ}$ and $270^{\circ}$ for all bias voltage from $-1.2 \mathrm{~V}$ to $1.2 \mathrm{~V}$, and the amplitude of TAMR increases with increasing bias voltage. While, for the other three samples, the bias and angle dependence of $R_{\mathrm{d}}$ are rather complicated compared to those reported in $\mathrm{CoFe}-\mathrm{MgO}-\mathrm{CoFe} \mathrm{MTJs}^{11}$ we can still extract some common features for the three samples. First, their bias dependence is asymmetric and the TAMR is large at low bias. Second, within the bias range around from $-0.3 \mathrm{~V}$ to $0.3 \mathrm{~V}$, the minimum of $R_{\mathrm{d}}$ is at $\theta=90^{\circ}$ and $270^{\circ}$,
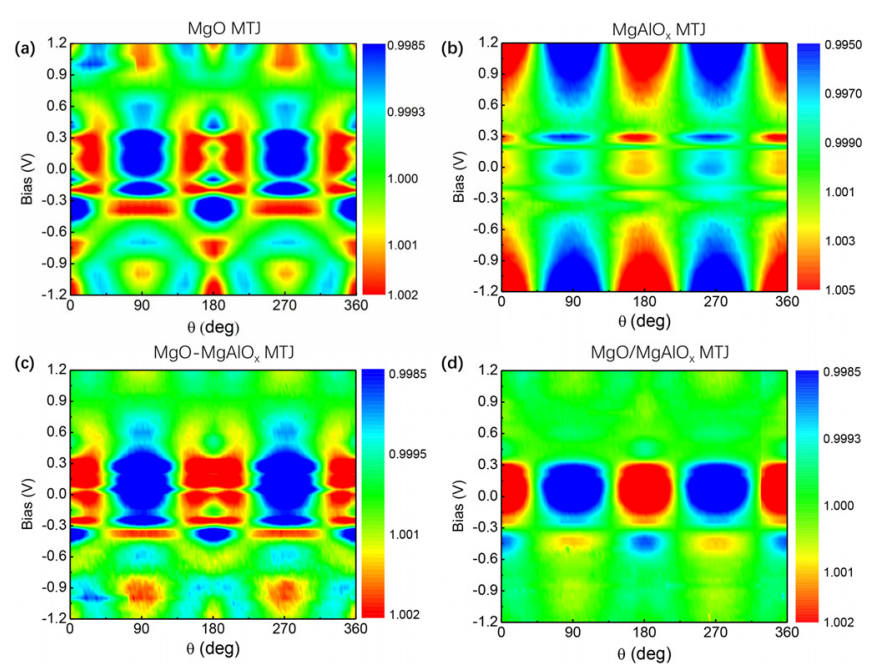

FIG. 3. Normalized $\mathrm{d} V / \mathrm{d} I$ as a function of bias voltage and angle $\theta$ for $\mathrm{MgO}$ (a), $\mathrm{MgAlO}_{\mathrm{x}}$ (b), $\mathrm{MgO}-\mathrm{MgAlO}_{\mathrm{x}}$ (c), and $\mathrm{MgO} / \mathrm{MgAlO}$ (d) $\mathrm{MTJ}$, respectively. The magnitude of $\mathrm{d} V / \mathrm{d} I$ is shown by the color. while for bias voltage below $-0.3 \mathrm{~V}$, the maximum of $R_{\mathrm{d}}$ locates at $\theta=90^{\circ}$ and $270^{\circ}$, indicating a sign change of TAMR. With further decreasing bias voltage, there is a sign change again in $\mathrm{MgO}$ and $\mathrm{MgO}-\mathrm{MgAlO}_{\mathrm{x}}$ MTJs but the $\mathrm{MgO} / \mathrm{MgAlO}_{\mathrm{x}} \mathrm{MTJ}$ remains the same. For bias below $-0.8 \mathrm{~V}$, there is a clear second set of peaks in $\mathrm{MgO}$ and $\mathrm{MgO}-\mathrm{MgAlO}_{\mathrm{x}} \mathrm{MTJ}$, indicating a clear evidence of fourfold symmetric angular dependence, but no obvious change was observed in $\mathrm{MgO} / \mathrm{MgAlO}_{\mathrm{x}}$ MTJs.

It is well known that the minority IRSs related to interfacial electronic structures also have an important impact on transport properties, ${ }^{18,30,31}$ which possibly accounts for the observed different TAMR behavior in MTJs with different barriers. To identify the minority IRSs, we performed the IETS measurement of the samples in the antiparallel (AP) state. It is easy to clarify the minority IRSs in the AP state when electrons tunnel from occupied majority states to unoccupied minority states. Figures 4(a)-4(d) show $\mathrm{d}^{2} I / \mathrm{d} V^{2}$ curves in the AP state at different temperatures for $\mathrm{MgO}$, $\mathrm{MgAlO}_{\mathrm{x}}, \mathrm{MgO} \mathrm{MgAlO}_{\mathrm{x}}$, and $\mathrm{MgO} / \mathrm{MgAlO}$ x MTJs, respectively. The insets are corresponding zoom-in of the area in the dashed square. For MgO MTJ, there are several clear peaks, which is consistent with the reported results. ${ }^{17}$ The peaks at $\pm 0.03 \mathrm{~V}$ can be attributed to magnon excitation ${ }^{32}$ related to the spin-flip events in the AP state. The peaks at $-0.16 \mathrm{~V}$ and $-1.0 \mathrm{~V}$ labeled as IRS1 and IRS2, respectively, are attributed to IRS at the bottom $\mathrm{Fe} / \mathrm{MgO}$ interface. It has been well established that both IRSs contain minority $\Delta_{1}$ states and minority $\Delta_{5}$ states, but IRS1 is dominated by minority $\Delta_{5}$ states, while IRS2 is dominated by minority $\Delta_{1}$ states. $^{17}$ The IRSs are very sensitive to chemical bonding ${ }^{17}$ and roughness or defects at the interface. ${ }^{18}$ No peaks were observed at positive bias, indicating that the IRSs vanished at the top $\mathrm{MgO} / \mathrm{Fe}$ interface due to the roughness of the top interface. For $\mathrm{MgAlO}_{\mathrm{x}} \mathrm{MTJ}$, no IRSs but only weak magnon peaks were observed. The disappearance of IRSs at the Fe/ $\mathrm{MgAlO}_{\mathrm{x}}$ interface is reasonable due to different electronic structures and interfacial environments. The lattice constant of the spinel $\mathrm{MgAl}_{2} \mathrm{O}_{4}$ barrier is twice that of the Fe electrode, resulting in the "band-folding" effect in $\mathrm{Fe},{ }^{21}$ which leads to different interfacial band structures. In addition, the stable $\mathrm{Fe} / \mathrm{MgAl}_{2} \mathrm{O}_{4}$ interface is $\mathrm{Fe}$ atoms on top of $\mathrm{O}$ atoms of $\mathrm{MgAl}_{2} \mathrm{O}_{4}$ with octahedral $\mathrm{Al}$ terminated, ${ }^{21}$ which is different from that of $\mathrm{MgO}$ MTJ.

For the $\mathrm{MgO}-\mathrm{MgAlO}_{\mathrm{x}}$ sample, the $\mathrm{d}^{2} I / \mathrm{d} V^{2}$ curve shows the same peaks of magnon, IRS1, and IRS2 as that of $\mathrm{MgO}$ MTJs. This proves that the $\mathrm{Fe} / \mathrm{MgO}-\mathrm{MgAlO}_{\mathrm{x}}$ interface is the same as that of $\mathrm{MgO} \mathrm{MTJ}$ and there is no Al diffusion into the interface during the annealing process. However, for $\mathrm{MgO} / \mathrm{MgAlO}_{\mathrm{x}} \mathrm{MTJ}$, there are only peaks of magnon and IRS 1 in the $\mathrm{d}^{2} I / \mathrm{d} V^{2}$ curve. This proves that the annealing process not only improves the crystal quality of the top $\mathrm{Fe}$ electrode but also modifies the bottom $\mathrm{Fe} / \mathrm{MgO}$ interface environment. The bottom Fe electrodes of $\mathrm{MgO}-\mathrm{MgAlO}_{\mathrm{x}}$ and $\mathrm{MgO} / \mathrm{MgAlO}_{\mathrm{x}}$ MTJs were annealed in situ to flatten the surface, and the barriers were grown in a two-dimensional layer-by-layer mode. The roughness of the bottom interfaces and crystal ordering of barriers should be the same for the two samples, which change slightly during annealing of the top $\mathrm{Fe}$ film in $\mathrm{MgO}-\mathrm{MgAlO}{ }_{\mathrm{x}}$ MTJ. The difference of 

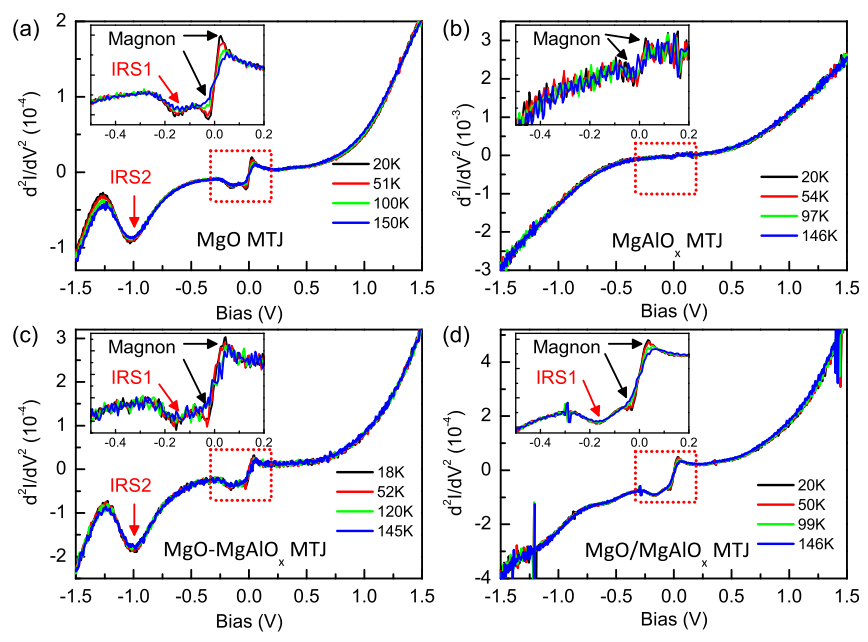

FIG. 4. Inelastic electron tunneling spectroscopy (IETS) in AP states at different temperatures for $\mathrm{MgO}(\mathrm{a}), \mathrm{MgAlO}_{\mathrm{x}}$ (b), $\mathrm{MgO}_{-} \mathrm{MgAlO}_{\mathrm{x}}$ (c), and $\mathrm{MgO} /$ $\mathrm{MgAlO}_{\mathrm{x}}$ (d) MTJs, respectively. Insets show the zoom-in of the area in the dashed square. Magnon peaks and IRSs are denoted.

interfaces for the two samples may be attributed to Fe oxide. In typical epitaxial $\mathrm{Fe} / \mathrm{MgO} / \mathrm{Fe} \mathrm{MTJ}$, the existence of $\mathrm{FeO}$ oxide at the bottom interface has been proposed. ${ }^{33}$ The Fe oxide at the un-annealed $\mathrm{Fe} / \mathrm{MgO}$ bottom interface may be different. It has been proved that the annealing process can transform the interfacial oxide from a more $\mathrm{Fe}_{2} \mathrm{O}_{3}$-like phase in the as-grown state to a more FeO-like phase. ${ }^{34}$ The modification of $\mathrm{Fe}$ oxide at the interface can account for the different IRSs in the $\mathrm{MgO}-\mathrm{MgAlO}_{\mathrm{x}}$ and $\mathrm{MgO} / \mathrm{MgAlO}$ x MTJs.

The role of IRS in transport can be evidenced by characterization of parallel conductance of MTJ. Figures 5(a)-5(d) show the parallel differential conductance at different temperatures for $\mathrm{MgO}, \mathrm{MgAlO}_{\mathrm{x}}, \mathrm{MgO}-\mathrm{MgAlO}_{\mathrm{x}}$, and $\mathrm{MgO} /$ $\mathrm{MgAlO}_{\mathrm{x}} \mathrm{MTJ}$, respectively. The conductance of MgO MTJ shows a bump between $\pm 0.25 \mathrm{~V}$, which is a typical feature of single crystal MgO MTJ. ${ }^{35}$ The bump reflects the majority $\Delta_{5}$ band structure of bulk Fe (001), which lies at about $0.2 \mathrm{eV}$ above the Fermi level. When the bias voltage is larger than $0.2 \mathrm{~V}$, the contribution from $\Delta_{5}$ states to the conductance is eliminated, resulting in a local minimum of the conductance. The conductance of $\mathrm{MgAlO}_{\mathrm{x}} \mathrm{MTJ}$ is quite flat between $\pm 0.25 \mathrm{~V}$. This indicates a negligible contribution from the $\Delta_{5}$ band compared with the $\Delta_{1}$ band due to large contribution of $\Delta_{1}$ states in both majority and minority channels in $\mathrm{P}$ states. $^{21}$ The $\mathrm{MgO}-\mathrm{MgAlO}_{\mathrm{x}}$ MTJ shows a similar characteristic to that of $\mathrm{MgO} \mathrm{MTJ}$, while we could not find any local minima in the conductance spectrum of the $\mathrm{MgO} /$ $\mathrm{MgAlO}_{\mathrm{x}}$ MTJ.

We argue that the different electronic structures are responsible for the different TAMR behaviors of the MTJs. The main difference of the TAMR is the symmetry of angular dependence, i.e., the proportion of fourfold symmetry in $\mathrm{MgO}$ and $\mathrm{MgO}-\mathrm{MgAlO}_{\mathrm{x}}$ MTJs is much higher than that in $\mathrm{MgAlO}_{\mathrm{x}}$ and $\mathrm{MgO} / \mathrm{MgAlO}_{\mathrm{x}}$ MTJs. The angular dependence of out-of-plane TAMR is twofold-symmetrical only if the second order of the SOC field is considered. ${ }^{29}$ The fourfold component of TAMR was also observed in sputtered $\mathrm{MgO}$ MTJ and attributed to the coupling of minority IRS and majority $\Delta_{1}$ band. $^{11}$ Furthermore, it has been confirmed that
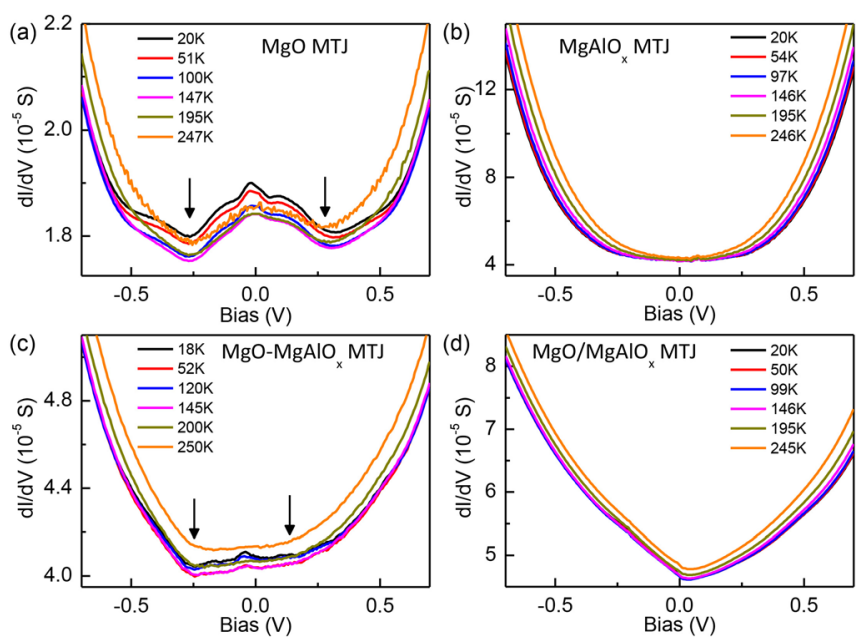

FIG. 5. Parallel differential conductance at different temperatures for $\mathrm{MgO}$ (a), $\mathrm{MgAlO}_{\mathrm{x}}$ (b), $\mathrm{MgO}-\mathrm{MgAlO}_{\mathrm{x}}$ (c), and $\mathrm{MgO} / \mathrm{MgAlO}{ }_{\mathrm{x}}$ (d) MTJs, respectively. The arrows in (a) and (c) denote the local minima of the conductance.

the IRS1 dominated by minority $\Delta_{5}$ states can mix with majority $\Delta_{1}$ states via SOC at the interface to generate new states in single crystal $\mathrm{Fe} / \mathrm{MgO} / \mathrm{Fe}$ MTJ. ${ }^{17}$ The new states contribute to the $\Delta_{5}$ related conductance bump mentioned above and result in an nonmonotonic temperature dependence of conductance at low bias. ${ }^{17}$ In our case, the parallel conductance within bump range shows nonmonotonic temperature dependence and minimum locates at around $T=150 \mathrm{~K}$, as shown in Figs. 5(a) and 5(c), which is consistent with the reported results. ${ }^{17}$ Therefore, we argue that the mixture of IRS1 and majority $\Delta_{1}$ states gives rise to the enhanced fourfold symmetric angular dependence of TAMR in $\mathrm{MgO}$ and $\mathrm{MgO}-\mathrm{MgAlO}_{\mathrm{x}}$ MTJs. The mixture state is not only a mixture of $\Delta_{1}$ and $\Delta_{5}$ symmetry but also the mixture of spin-up and spin-down, which can contribute to the parallel conductance with both negative bias and positive bias, resulting in the related local minimum of parallel conductance. Thus, $A_{4} / A_{0}$ is symmetric as a function of voltage though the IRS can only be detected in negative bias. For $\mathrm{MgO} / \mathrm{MgAlO} \mathrm{xTJ}_{\mathrm{x}}$, the IRS1 cannot mix with majority $\Delta_{1}$ states efficiently, which can be confirmed by the featureless parallel conductance. Thus, $\mathrm{MgO} / \mathrm{MgAlO}_{\mathrm{x}}$ MTJ shows a much weaker fourfold symmetric angular dependence of TAMR. For the same reason, $\mathrm{MgAlO}_{\mathrm{x}}$ MTJ without of IRSs shows a main twofold symmetric angular dependence of TAMR.

In summary, we fabricated four different fully epitaxial MTJs with the core structure of $\mathrm{Fe} /$ Barrier/Fe (001), where

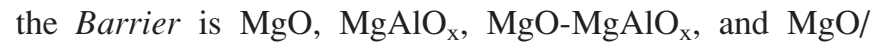
$\mathrm{MgAlO}_{\mathrm{x}}$, respectively. All the Fe layers were in situ annealed to improve the crystal quality and flatten the surface except the top Fe layer of $\mathrm{MgO} / \mathrm{MgAlO}_{\mathrm{x}} \mathrm{MTJ}$. The highest TMR ratio is obtained in $\mathrm{MgO}$ MTJ, while $\mathrm{MgO} /$ $\mathrm{MgAlO}_{\mathrm{x}}$ MTJ shows the lowest TMR. The TAMR effect in these MTJs was characterized at $10 \mathrm{~K}$ with the magnetization of Fe tilted from in-plane to out-of-plane at different bias voltages. The angular dependence of TAMR shows the main twofold symmetry in $\mathrm{MgAlO}_{\mathrm{x}}$ and $\mathrm{MgO} / \mathrm{MgAlO}_{\mathrm{x}}$ MTJs, but an enhanced fourfold symmetry was observed in $\mathrm{MgO}$ and $\mathrm{MgO}-\mathrm{MgAlO}_{\mathrm{x}}$ MTJs. By measuring the IETS in AP states 
and parallel conductance, we found that the IRS dominated by minority $\Delta_{5}$ states can mix with majority $\Delta_{1}$ states in $\mathrm{MgO}$ and $\mathrm{MgO}-\mathrm{MgAlO}_{\mathrm{x}} \mathrm{MTJ}$, giving rise to the enhanced fourfold symmetric angular dependence of TAMR.

See supplementary material for the temperature dependence of parallel and antiparallel resistance for all the samples.

This project was supported by the National Key Research and Development Program of China (Grant No. 2017YFA0206200) and the National Natural Science Foundation of China (NSFC, Grant Nos. 11434014, 51620105004, 51701203, and 11674373) and partially supported by the Strategic Priority Research Program (B) (Grant No. XDB07030200), the International Partnership Program (No. 112111KYSB20170090), and the Key Research Program of Frontier Sciences (Grant No. QYZDJSSW-SLH016) of the Chinese Academy of Sciences (CAS). Y.L. also acknowledges the support from the Joint French National Research Agency (ANR)-NSFC of China (NSFC) SISTER Project (Grant Nos. ANR-11-IS10-0001 and NNSFC 61161130527) and ENSEMBLE Project (Grant Nos. ANR-14-0028-01 and NNSFC 61411136001). B.S.T. also acknowledges the China Postdoctoral Science Foundation Funded Project (Grant No. 2016M601130).

${ }^{1}$ M. Julliere, Phys. Lett. A 54, 225 (1975).

${ }^{2}$ T. Miyazaki and N. Tezuka, J. Magn. Magn. Mater. 139, L231 (1995).

${ }^{3}$ J. S. Moodera, L. R. Kinder, T. M. Wong, and R. Meservey, Phys. Rev. Lett. 74, 3273 (1995).

${ }^{4}$ S. S. Parkin, C. Kaiser, A. Panchula, P. M. Rice, B. Hughes, M. Samant, and S. H. Yang, Nat. Mater. 3, 862 (2004).

${ }^{5}$ S. Yuasa, T. Nagahama, A. Fukushima, Y. Suzuki, and K. Ando, Nat. Mater. 3, 868 (2004).

${ }^{6}$ C. Gould, C. Ruster, T. Jungwirth, E. Girgis, G. M. Schott, R. Giraud, K. Brunner, G. Schmidt, and L. W. Molenkamp, Phys. Rev. Lett. 93, 117203 (2004).

${ }^{7}$ C. Fang, C. H. Wan, B. S. Yang, J. Y. Qin, B. S. Tao, H. Wu, X. Zhang, X. F. Han, A. Hoffmann, X. M. Liu, and Z. M. Jin, Phys. Rev. B 96, 134421 (2017).

${ }^{8}$ C. Ruster, C. Gould, T. Jungwirth, J. Sinova, G. M. Schott, R. Giraud, K. Brunner, G. Schmidt, and L. W. Molenkamp, Phys. Rev. Lett. 94, 027203 (2005).

${ }^{9}$ H. Saito, S. Yuasa, and K. Ando, Phys. Rev. Lett. 95, 086604 (2005).

${ }^{10}$ A. N. Chantis, K. D. Belashchenko, E. Y. Tsymbal, and M. van Schilfgaarde, Phys. Rev. Lett. 98, 046601 (2007).

${ }^{11}$ L. Gao, X. Jiang, S. H. Yang, J. D. Burton, E. Y. Tsymbal, and S. S. Parkin, Phys. Rev. Lett. 99, 226602 (2007).

${ }^{12}$ J. Moser, A. Matos-Abiague, D. Schuh, W. Wegscheider, J. Fabian, and D. Weiss, Phys. Rev. Lett. 99, 056601 (2007).
${ }^{13}$ B. G. Park, J. Wunderlich, D. A. Williams, S. J. Joo, K. Y. Jung, K. H. Shin, K. Olejnik, A. B. Shick, and T. Jungwirth, Phys. Rev. Lett. 100, 087204 (2008).

${ }^{14}$ X. Z. Chen, J. F. Feng, Z. C. Wang, J. Zhang, X. Y. Zhong, C. Song, L. Jin, B. Zhang, F. Li, M. Jiang, Y. Z. Tan, X. J. Zhou, G. Y. Shi, X. F. Zhou, X. D. Han, S. C. Mao, Y. H. Chen, X. F. Han, and F. Pan, Nat. Commun. 8, 449 (2017).

${ }^{15}$ A. D. Giddings, M. N. Khalid, T. Jungwirth, J. Wunderlich, S. Yasin, R. P. Campion, K. W. Edmonds, J. Sinova, K. Ito, K. Y. Wang, D. Williams, B. L. Gallagher, and C. T. Foxon, Phys. Rev. Lett. 94, 127202 (2005).

${ }^{16}$ S. Hatanaka, S. Miwa, K. Matsuda, K. Nawaoka, K. Tanaka, H. Morishita, M. Goto, N. Mizuochi, T. Shinjo, and Y. Suzuki, Appl. Phys. Lett. 107, 082407 (2015).

${ }^{17}$ Y. Lu, H. X. Yang, C. Tiusan, M. Hehn, M. Chshiev, A. Duluard, B. Kierren, G. Lengaigne, D. Lacour, C. Bellouard, and F. Montaigne, Phys. Rev. B 86, 184420 (2012).

${ }^{18}$ P. J. Zermatten, G. Gaudin, G. Maris, M. Miron, A. Schuhl, C. Tiusan, F. Greullet, and M. Hehn, Phys. Rev. B 78, 033301 (2008).

${ }^{19}$ H. Sukegawa, H. Xiu, T. Ohkubo, T. Furubayashi, T. Niizeki, W. Wang, S. Kasai, S. Mitani, K. Inomata, and K. Hono, Appl. Phys. Lett. 96, 212505 (2010).

${ }^{20}$ J. Zhang, X. G. Zhang, and X. F. Han, Appl. Phys. Lett. 100, 222401 (2012).

${ }^{21}$ Y. Miura, S. Muramoto, K. Abe, and M. Shirai, Phys. Rev. B 86, 024426 (2012).

${ }^{22}$ H. Sukegawa, Y. Miura, S. Muramoto, S. Mitani, T. Niizeki, T. Ohkubo, K. Abe, M. Shirai, K. Inomata, and K. Hono, Phys. Rev. B 86, 184401 (2012).

${ }^{23}$ B. S. Tao, D. L. Li, H. F. Liu, H. X. Wei, J. F. Feng, S. G. Wang, and X. F. Han, IEEE Trans. Magn. 50, 4401004 (2014).

${ }^{24}$ B. S. Tao, D. L. Li, Z. H. Yuan, H. F. Liu, S. S. Ali, J. F. Feng, H. X. Wei, X. F. Han, Y. Liu, Y. G. Zhao, Q. Zhang, Z. B. Guo, and X. X. Zhang, Appl. Phys. Lett. 105, 102407 (2014).

${ }^{25}$ Ikhtiar, H. Sukegawa, X. Xu, M. Belmoubarik, H. Lee, S. Kasai, and K. Hono, Appl. Phys. Lett. 112, 022408 (2018).

${ }^{26}$ B. S. Tao, H. X. Yang, Y. L. Zuo, X. Devaux, G. Lengaigne, M. Hehn, D. Lacour, S. Andrieu, M. Chshiev, T. Hauet, F. Montaigne, S. Mangin, X. F. Han, and Y. Lu, Phys. Rev. Lett. 115, 157204 (2015).

${ }^{27}$ F. Bonell, S. Andrieu, A. M. Bataille, C. Tiusan, and G. Lengaigne, Phys. Rev. B 79, 224405 (2009).

${ }^{28}$ J. Crangle and G. M. Goodman, Proc. R. Soc. London, Ser. A 321, 477 (1971).

${ }^{29}$ A. Matos-Abiague, M. Gmitra, and J. Fabian, Phys. Rev. B 80, 045312 (2009).

${ }^{30}$ C. Tiusan, J. Faure-Vincent, C. Bellouard, M. Hehn, E. Jouguelet, and A. Schuhl, Phys. Rev. Lett. 93, 106602 (2004).

${ }^{31}$ K. D. Belashchenko, J. Velev, and E. Y. Tsymbal, Phys. Rev. B 72, 140404(R) (2005).

${ }^{32}$ V. Drewello, J. Schmalhorst, A. Thomas, and G. Reiss, Phys. Rev. B 77, 014440 (2008).

${ }^{33}$ S. G. Wang, G. Han, G. H. Yu, Y. Jiang, C. Wang, A. Kohn, and R. C. C. Ward, J. Magn. Magn. Mater. 310, 1935 (2007).

${ }^{34}$ D. Telesca, B. Sinkovic, S.-H. Yang, and S. S. P. Parkin, J. Electron Spectrosc. Relat. Phenom. 185, 133 (2012).

${ }^{35}$ C. Tiusan, F. Greullet, M. Hehn, F. Montaigne, S. Andrieu, and A. Schuhl, J. Phys.: Condens. Matter 19, 165201 (2007). 